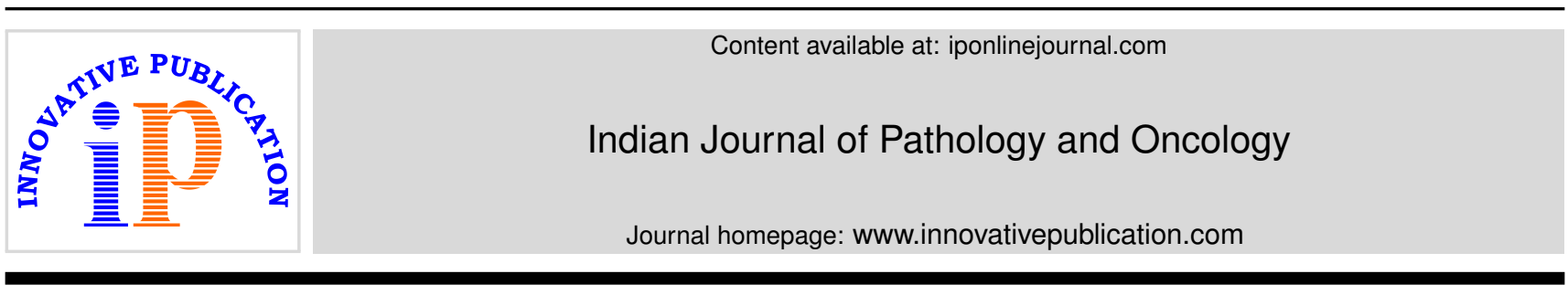

\title{
Editorial
}

\section{COVID-19: What you need to know}

\author{
Ranjan Agrawal ${ }^{1, *}$ \\ ${ }^{1}$ Dept. of Pathology, Rohilkhand Medical College \& Hospital, Bareilly, Uttar Pradesh, India
}

\section{A R T I C L E I N F O}

Article history:

Received 27-04-2020

Accepted 28-04-2020

Available online 25-05-2020
(C) 2020 Published by Innovative Publication. This is an open access article under the CC BY-NC-ND license (https://creativecommons.org/licenses/by/4.0/)
Coronavirus or COVID-19 is presently named as SARS-CoV-2 meaning severe acute respiratory syndrome coronavirus-2 also termed as human coronavirus 2019 (HCoV-19). Much knowledge has already been disseminated via newspaper, media and social networking. My purpose of writing this editorial is to provide information and message wherein the mode of transmission of the virus and the preventive measures should be known to all.

As per the information available the first case was reported from Wuhan (China) wherein it was reported to occur as animal transmitted infection which later turned into human to human transmission. According to the various studies and literature available air borne is one of the commonest modes of transmission. The virus is transmitted via the aerosol droplets either by sneezing or coughing to anybody who is in close proximity. These droplets may also be deposited on the surfaces of door handles, tables, utensils, computer keyboards, mouse, pen etc. Alongwith these, a cool and humid environment further aggravates the chances of virus remaining live or to be deposited on the surfaces. Regular sanitization of the surface room and utility items by using alcohol based liquids may reduce the chances of further transmission. Similarly, regular and frequent hand washing may further help. In offices, 'social distancing' should be strictly adhered to. Even in the clinics and hospitals only a single attendant should be allowed alongwith each admitted patient. The space between each

\footnotetext{
* Corresponding author.

E-mail address: drranjan68@gmail.com (R. Agrawal).
}

bed should also be increased. Spitting in the vicinity should be strictly prohibited. Workers should permanently wear masks that are three-ply or the proper N-95 masks. Use of gloves, paper napkins instead of towels, no sharing of items and regular disinfection should be the rule.

Full precautions should be taken by the people who plan to travel outside from their native place. Use of airconditioned coaches in trains or buses should be avoided as it is known to create a closed compartment for favorable environmental transmission. Highly efficient air filters are not used routinely so again the transmission rate is severe. Regular sanitization and fumigation of transport vehicles after each travel should be followed. Also, overcrowding during travelling should not be allowed. People should not only cover their face but also maintain a safe distance.

Residents especially in densely populated areas should maintain utter precautions, besides 'social distancing'. In case there is an infected person in the house, all furnitures and items should be removed from that room. While taking care of the person personal protective equipments (PPE) including facial mask, head cover, hand gloves and eye wear should be used judiciously. Moreover the payment medium should also be shifted to digital rather than currency notes or coins. Food packets and parcels should be properly washed and disinfected before use. Fruits and vegetables also should be washed thoroughly under running water or soaked in warm water for some time before cooking.

Healthcare professionals and workers are at the greatest risk of getting infected. An added threat of hospital acquired 
(Nosocomial) infection further add to the threat. Use of medical instruments and equipments should be with utmost care and precaution. Doctors and paramedicals are at the higher risk since in an OPD setting it is not known as who is infected and who is not. Although routine OPDs have been closed all over India still in Emergency cases adequate distancing between the attendants is also to be maintained. Any recent travel to an epidemic place or contact with any infected person should be immediately informed to the concerned doctor, so that adequate measures can be undertaken.

Adequate and timely precautions can thus not only avoid the spread of infection but also prevent an epidemic to occur.
It is for all the people to be alert and alarmed. Through this editorial my main purpose was to make every reader aware about the alarming situation prevailing and what measures should be taken for its prevention or further spread in the community.

\section{Author biography}

Ranjan Agrawal Professor

Cite this article: Agrawal R. COVID-19: What you need to know. Indian J Pathol Oncol 2020;7(2):194-195. 